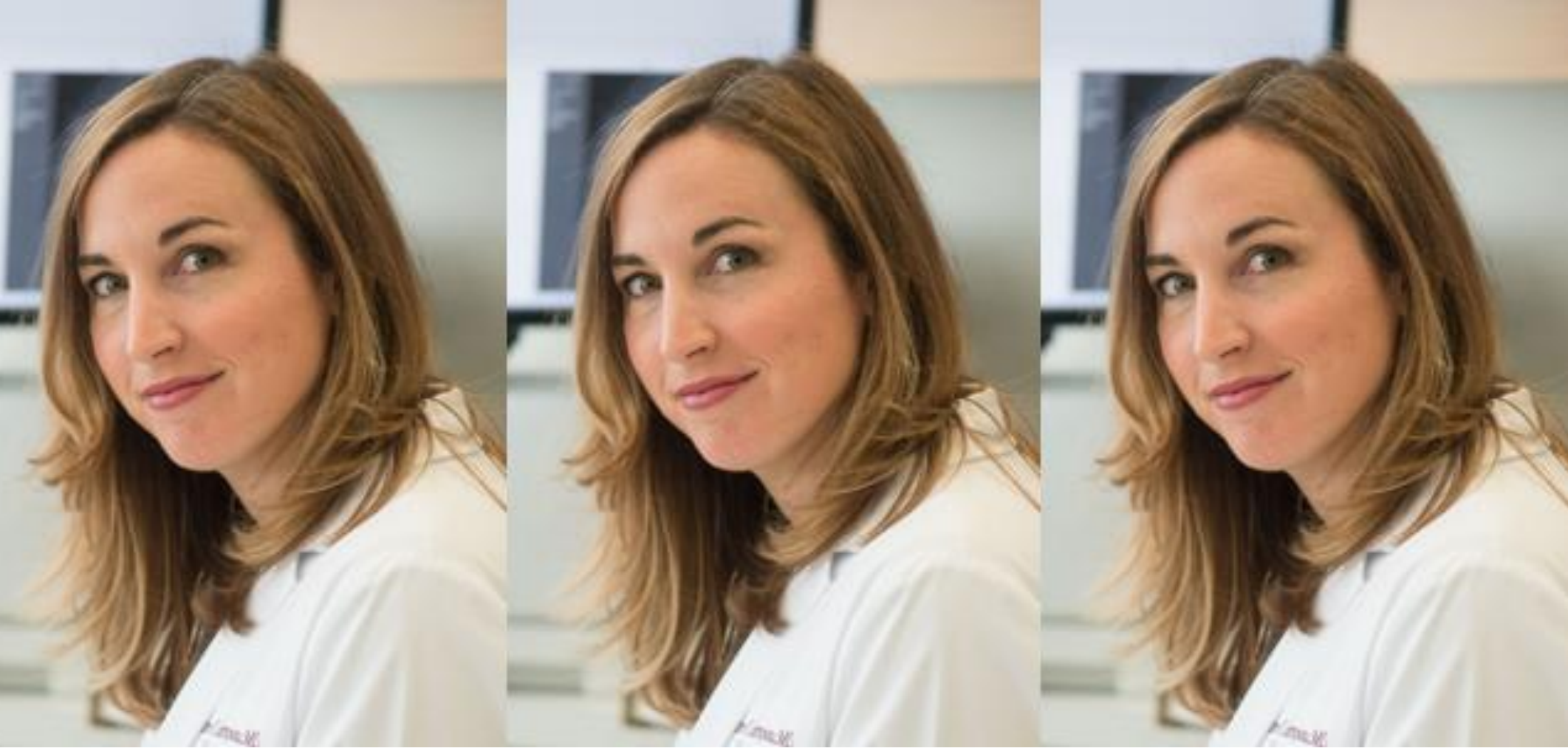

\title{
Reflections
}

\section{Successful Women in Medicine: Dr. Lysanne Campeau}

Geneviève Peel ${ }^{1}$

MJM 2020 18(8)

\section{ABSTRACT}

Dr. Lysanne Campeau (M.D., C.M., Ph.D., F.R.C.S.C.) is an Assistant Professor of Urology at McGill University's Jewish General Hospital. Through her flamboyant career in medicine, her research accomplishments, and her advocacy work for gender equality in medicine, she is a model of ambition, dedication, and passion. Dr. Campeau completed medical school as well as her urology residency at McGill University. She is the first woman to complete her entire residency at McGill University in this specific field. Dr. Campeau then went on to complete a clinical fellowship in Female Pelvic Medicine and Reconstructive Surgery at New York University, as well as a Ph.D. in Physiology and Pharmacology at Wake Forest Institute for Regenerative Medicine. She then came back to work as a urologist at the Jewish General Hospital and a clinical researcher at the Lady Davis Institute. Her research interests lie in female pelvic medicine, voiding dysfunction, and urogenital reconstruction. In addition to her clinical and academic duties, Dr. Campeau is involved in teaching urology residents as well as in some volunteer endeavours in the community. A resilient person, Dr. Campeau builds on her experience of gender discrimination in medicine to advocate for equality in her field. She also aims to raise awareness on the topic of incontinence, which is often taboo among the public. Through awareness campaigns as well as her innovative research in the field, Dr. Campeau works to develop new treatments and improve outcomes for patients who suffer from this condition. Dr. Campeau is a positive leader and role model for aspiring female physicians to whom she

\footnotetext{
${ }^{1}$ Faculty of Medicine, McGill University, Montreal, Quebec, Canada.

Corresponding Author: Geneviève Peel, email genevieve.peel@mail.mcgill.ca
} 
advises to cultivate adaptiveness, integrity, and honesty in order to navigate the challenging journey that is medicine.

\section{Dr. Lysanne Campeau M.D.C.M., Ph.D., F.R.C.S.C., Assistant Professor of Urology, McGill University}

Very few physicians exemplify the ambition, dedication, and passion for medicine as well as Dr. Lysanne Campeau (M.D.C.M., Ph.D., F.R.C.S.C.), an Assistant Professor of Urology at McGill University's Jewish General Hospital.

Born into a French-speaking family in Montreal's West Island, Dr. Campeau showed fascination and curiosity for physiology and biomechanics at a very early age. "I remember being very young and looking at my hands, wondering how they could move the way they did," she recalls. Her scientific mind and her love of learning were encouraged by parents, especially given that they did not instill any stereotypical gender roles on her. Growing up with two brothers, Dr. Campeau remembers always feeling on equal grounds with them. She played the same sports as them and never felt any lesser despite the times. With this unfettered interest, she was offered a scholarship to the private Collège André-Grasset where she completed her CEGEP diploma. By that time, she knew she wanted to pursue a career in a health-related field.

McGill University was an obvious first choice for Dr. Campeau when came the time to apply to medical school; the university's openness to the world as well as its reputation for excellence greatly appealed to her. Once in medical school, a classmate suggested she would enjoy doing an elective in urology, which she did. At the time, there were no women on staff and a single female resident, making her a self-dubbed "rare species." Her affirmative personality and irreproachable work ethics were quickly noticed, and she received support from both residents and staff as she began to get involved in the field.

After graduating from medical school in 2005, Dr. Campeau entered her urology residency at McGill. Although she describes it as a very challenging time of her life involving hard work and long hours, Dr. Campeau enjoyed residency. She was passionate about the work and enjoyed the team aspect of surgery. She nonetheless faced certain gender-based obstacles during these years. She remembers having challenging encounters with more junior residents that did not always accept being led by a woman. "This was a different time," she states, "and these people were a product of their time. To me, this kind of interaction was not surprising; it was simply the norm."

When asked what specific challenges female residents can expect currently, Dr. Campeau explained that women have to maintain a certain attitude to succeed in medicine. In her opinion, being adaptive is key, as it allows you to approach and interact with a person in a way that is tailored to this specific relationship dynamic. "I don't interact with male colleagues the same way I do with other professionals I work with," she describes. She also specifies that aside from a few specific occasions, she mostly felt equal to her male counterparts as a resident trainee. Dr. Campeau graduated from residency in 2010, becoming the first woman to complete her entire urology residency at McGill University. Having considered gynecology before choosing urology, Dr. Campeau chose to join these two fields of interest and went on to complete a fellowship in Female Pelvic Medicine and Reconstructive Surgery at New York University. With her eye toward academics, she sought opportunities to combine research to her clinical fellowship and was soon offered a scholarship to complete her Ph.D. in Physiology and Pharmacology at the Wake Forest Institute for Regenerative Medicine. This resulted in Dr. Campeau obtaining board certification from the American Board of Urology as well as in her specialty of Female Pelvic Medicine and Reconstructive Surgery, on top of her Canadian Royal College Certification in Urology.

Her positive experience as a resident at McGill and the constructive relationships she fostered with her colleagues during her residency brought Dr. Campeau back to Montreal to work at the Jewish General Hospital as a staff. She also became a clinical researcher at the Lady Davis Institute, leading innovative research on the topics of female pelvic medicine, voiding dysfunction, and urogenital reconstruction.

After several years working in this domain, she enjoys being able to develop long-term relationships with her patients. She also appreciates the breadth of practice that urology offers; she remembers being astonished as a resident at the variety of different surgeries she could perform within a single day - from microsurgery to open abdominal interventions to robotic surgery. She also values the possibility of offering her patients behavioral, medical, 
and surgical treatment, with the option of surgery being used as a last resort when other treatments have failed. This brings her satisfaction in knowing she is making a difference for patients who are truly suffering. "Incontinence is not a sexy subject. It is often a taboo subject among the public," says Dr. Campeau. "But it affects vulnerable individuals whose voices aren't necessarily heard, so it's important to bring this topic to light." For this purpose, Dr. Campeau has volunteered her time for The Canadian Continence Foundation's campaign on overactive bladder in collaboration with Châtelaine, appearing in a promotional video(1) encouraging people to seek treatment for this condition.

When asked if she considers herself a feminist, Dr. Campeau answers affirmatively without hesitation. She notices that people often misunderstand the term, interpreting it as women being superior to men, when in truth it refers to gender equality. In her opinion, because there remains a considerable amount of inequities and discrimination towards women in the society we live in, being a feminist and speaking out on these issues is crucial. She adds that her husband and her sometimes reflect on this together as well when thinking of their two daughters and how they will move through the world. Dr. Campeau engages in feminist advocacy in her work as Assistant Professor of Urology and site director for residency training at the Jewish General Hospital. As the coordinator of the residents' monthly journal club, she includes an article pertaining to gender disparities within the medical field almost every month. Whether it be in the vocabulary used by staff to evaluate residents or the words used when writing a research proposal, she explains that there still exists a noticeable difference in the way men and women are portrayed and portray themselves in medicine. She once had a research mentor tell her she didn't brag about herself enough when writing her research proposals. "Now I try to think, "how would I write about the importance of my research to convince the research panel, if I were a man?"”

Dr. Campeau also recalls moments in her career when she experienced these disparities. There were times when she was mistaken for a nurse, or had a patient address her male junior resident when she was the chief resident who performed the patient's surgery. She also feels that as a female physician, she is held to a higher standard when it comes to appearing professionally dressed, for example. She reiterates, however, that people holding these admittedly outdated beliefs are products of their generation. Dr. Campeau's impressive career and countless academic and clinical achievements at a young age are a testament to her ability to brush off these events, remain focused on her goals, and devote her energy to providing the best care for all her patients. "I can see that the newer generation of female residents experiences less and less this pressure to achieve the double standard, and it's encouraging," she says. After being the only woman on staff in urology at the JGH for 5 years, Dr. Campeau was recently joined by Dr. Mélanie Aubé-Peterkine and is thrilled to see that women are carving out a place for themselves in this field. Dr. Campeau is also a member of the Society for Women in Urology, which provides a space to discuss and share the realities, challenges, and positive experiences of being a female physician in the field.

To aspiring female physicians, residents, and students, Dr. Campeau advises to remain adaptive in every situation they encounter, stressing that this is a skill that is useful during training and in practice afterwards. She also states the importance of believing in one's convictions and not letting other people's opinions push you to make one decision or another. To her, integrity and honesty remain key qualities that will result in positive outcomes throughout one's life. She also explains that one's professional reputation begins to shape itself from the first moments of medical school, thereby highlighting the importance of maintaining constructive and agreeable working relationships: "As I was reading books on childhood education when becoming a new mother, I came across this Maya Angelou quote: 'People will forget what you said, people will forget what you did, but people will never forget how you made them feel.' I believe this is true in medicine as well; being the first author or obtaining a prestigious scholarship are remarkable achievements we as doctors should strive for, but not at the cost of doing dishonest things, stepping on other people, or making others feel bad."

\section{References}

$\begin{aligned} & \text { 1. 2019, M. L. P. C. O. M. } 19 \text { décembre. (2019, December 19). Gérer la vessie } \\ & \text { hyperactive. Retrieved March } 17, \quad 2020,\end{aligned}$
https://fr.chatelaine.com/commandite/gerer-la-vessie-hyperactive 